\title{
CRESCIMENTO DE MUDAS DE Eucalyptus grandis EM DIFERENTES TAMANHOS DE TUBETES E FERTILIZAÇÃO N-P-K ${ }^{1}$
}

\author{
José Mauro Gomes², Laércio Couto ${ }^{2}$, Helio Garcia Leite ${ }^{3}$, Aloisio Xavier ${ }^{3}$ e Silvana Lages Ribeiro Garcia ${ }^{4}$
}

\begin{abstract}
RESUMO - O experimento foi instalado com o objetivo de estudar o crescimento de mudas de Eucalyptus grandis produzidas em diferentes tamanhos de tubetes e fertilização N-P-K. O substrato utilizado foi uma mistura de $80 \%$ de composto orgânico (CO) e de $20 \%$ de moinha de carvão (MC), adubados com a presença e ausência dos elementos $\mathrm{N}, \mathrm{P}$ e K. Como embalagens foram utilizados quatro tamanhos de tubetes de plástico rígido, com volumes de 50,110, 200 e $280 \mathrm{~cm}^{3}$. Os volumes dos tubetes devem ser considerados para produção de mudas de Eucalyptus grandis. Apesar de os melhores crescimentos terem sido obtidos nos maiores tubetes, estes não devem ser utilizados, uma vez que as alturas das mudas estão acima das tecnicamente ótimas para o plantio, além de o custo de produção ser onerado. Aos 60 dias de idade as mudas ainda estão pequenas e bastante tenras, sem o endurecimento adequado para o plantio no campo. Aos 120 dias após a semeadura a restrição ao crescimento das raízes e da altura das mudas é afetada, mesmo nos tubetes de maiores volumes, não sendo essa a idade indicada. $\mathrm{O}$ tubete de $110 \mathrm{~cm}^{3}$ de volume deve ser considerado para mudas com 90 dias de idade.
\end{abstract}

Palavras-chave: Eucalipto, embalagem, mudas e viveiro.

\section{GROWTH OF Eucalyptus grandis SEEDLINGS PRODUCED IN DIFFERENT SIZED TUBES AND N-P-K'FERTILIZATION}

\begin{abstract}
An experiment was carried out to study the growth of Eucalyptus grandis seedlings produced in different sized tubes and N-P-K fertilization. A mixture of $80 \%$ organic compound (CO) and $20 \%$ charcoal powder fertilized with and without $N, P$ and $K$ was used as substrate. Four sizes of hard plastic tubes at the volumes of 50, 110, 200 and $280 \mathrm{~cm}^{3}$ were used as containers. The tube volumes must be considered for producing Eucalyptus grandis seedlings. Although the highest growths occurred in the larger tubes, these tubes should not be used because the seedling heights far surpass the ones considered as technically optimum for planting, and have a higher production cost. At 60 days of age, the seedlings are still small and quite tender, and do not present the hardness appropriate to field planting. At 120 days after sowing, the restriction to root growth and seedling height is affected even in the larger tubes, thus this is not the indicated age. The $110 \mathrm{~cm}^{3}$ volume tube must be considered for 90-day old seedlings.
\end{abstract}

Key words: $\quad$ Eucalypt, containers, seedlings and nursery.

\section{INTRODUÇÃO}

A produção de mudas em recipientes é o sistema mais utilizado, principalmente por permitir a melhor qualidade, devido ao melhor controle da nutrição e à proteção das raízes contra os danos mecânicos e a desidratação, além de propiciar o manejo mais adequado no viveiro, no transporte, na distribuição e no plantio.

Devido à maior proteção das raízes o período de plantio poderá ser prolongado, uma vez que essas não se danificam durante $\mathrm{o}$ ato de plantar, promovendo maiores

1 Recebido para publicação em 24.9.2001.

Aceito para publicação em 19.2.2003.

2 Professor Titular de Departamento de Engenharia Florestal da Universidade Federal de Viçosa - DEF/UFV, 36571-000 ViçosaMG; ${ }^{3}$ Professor Adjunto de Departamento de Engenharia Florestal da UFV. ${ }^{4}$ Engenheira Florestal, M.S., Faculdade de Viçosa, 36571-000 Viçosa-MG. 
índices de sobrevivência e de crescimento (Daniel et al., 1982; Santos et al., 2000).

O tipo de recipiente e suas dimensões exercem influências sobre a qualidade e os custos de produção de mudas de espécies florestais (Carneiro, 1987).

Os volumes dos recipientes influenciam a disponibilidade de nutrientes e água (Böhm, 1979), devendo ser ressaltado que o maior volume promove a melhor arquitetura do sistema radicular, à semelhança do sistema radicular de mudas por semeadura direta no campo (Parviainen,1976), apesar de grandes dimensões acarretarem maiores custos de produção, de transporte, de distribuição e de plantio (Gonzalez, 1988; Gomes et al., 1990), e a altura e o diâmetro variarem com a espécie (Ferreira, 1985; Carneiro, 1987; Gomes et al., 1990). No entanto, em geral, a altura da embalagem é mais importante do que o seu diâmetro para o crescimento de mudas de várias espécies florestais (Gomes et al., 1980, 1981, 1990).

Outro aspecto a ser considerado é a durabilidade da embalagem, ou seja, ela não poderá se desintegrar durante o período de produção das mudas, nem demorar muito tempo para se decompor no campo (Carneiro, 1995).

Diferentes recipientes utilizados na produção de mudas foram estudados por diversos pesquisadores (Bertolani et al., 1975; Barros et al., 1978; Gomes et al., 1977, 1985, 1991). De acordo com a maioria deles, o saco plástico superou os demais, apresentando algumas desvantagens como o enovelamento do sistema radicular, a utilização de grandes áreas no viveiro, o uso de terra de subsolo como substrato, o alto custo do transporte das mudas para o campo e o baixo rendimento nas operações de distribuição e de plantio no campo.

Pesquisas foram realizadas com o objetivo de minimizar as desvantagens das principais embalagens existentes, principalmente as referentes aos sacos plásticos, porém os resultados não foram satisfatórios (Gomes et al., 1981).

A produção de mudas em recipientes de paredes lisas, à semelhança das sacolas plásticas, provoca o enovelamento do sistema radicular (Parviainen, 1981), o que continua na fase de campo e provoca a baixa estabilidade das futuras árvores (Schimidt-Voght, 1984), devendo ser ressaltado que as deformações do sistema radicular em mudas de Pinus spp. (Parviainen \& Tervo, 1989), de Pinus taeda e de Pinus elliottii (Carneiro, 1987) continuam causando sérios problemas no campo. Além disto,

R. Árvore, Viçosa-MG, v.27, n.2, p.113-127, 2003 apresentam baixa sobrevivência e crescimento inicial, por não ter um sistema radicular eficiente, podendo culminar em morte antes dos dois anos de idade ou permanecer, até a idade de corte, como uma árvore suprimida.

As pesquisas com embalagens para produção de mudas têm sido muito dinâmicas e sempre acatando o princípio de que o sistema radicular é importante, devendo apresentar boa arquitetura, e que, por ocasião do plantio, deverá sofrer o mínimo de distúrbios, o que permite que a muda seja plantada com um torrão sólido e bem agregado a todo o sistema radicular, favorecendo a sobrevivência e o crescimento inicial no campo.

A tendência atual é a substituição das sacolas plásticas pelos tubetes de plástico rígido, por apresentarem estrias longitudinais internas, minimizando os problemas, principalmente no que se refere ao enovelamento do sistema radicular (Carneiro, 1985; Gomes et al., 1990), além de possibilitar a mecanização das operações de produção de mudas (Carneiro, 1995).

Os recipientes pequenos, tipo tubetes de plástico rígido, restringem o crescimento do sistema radicular, portanto não são indicados para produção de mudas de Eucalyptus camaldulensis, E. grandis e E. cloeziana (Reis et al., 1989).

Os tubetes pequenos $\left(50 \mathrm{~cm}^{3}\right)$ podem causar menor crescimento no viveiro, mas o crescimento em altura de Eucalyptus grandis é recuperado no campo (BARROS et al., 1978), sendo indicadas, em relatos técnicos, algumas vantagens para o seu uso (Campinhos \& Ikemori, 1983; Fagundes \& Fialho, 1987).

A utilização dos tubetes de plástico rígido de $50 \mathrm{~cm}^{3}$ de volume, tendo como substrato a mistura de composto orgânico com moinha de carvão, proporcionou ao Eucalyptus grandis um sistema radicular bem mais agregado ao substrato (Gomes et al., 1985), sendo também mais agregado e apresentando uma significativa diferença quando comparado ao das mudas produzidas em sacolas plásticas (Gonçalves, 1987).

Hoje o mercado oferece tamanhos e formas diferenciadas de tubetes, indicados para várias espécies, mas ainda é carente de informações para produção de mudas, até mesmo de eucaliptos, que foi a espécie mais pesquisada nesse tipo de recipiente.

Na produção de mudas de eucaliptos foram testados modelos de tubetes, sendo indicado o de seção circular com $50 \mathrm{~cm}^{3}$; essa introdução revolucionou os viveiros, 
trazendo avanços no processo de produção (Zani Filho et al.,1989), apesar de os de diferentes tamanhos serem mais adequados para outras espécies.

Na produção de mudas de Eucalyptus grandis, 90 dias após a semeadura, os tubetes de $50 \mathrm{~cm}^{3}$ foram mais adequados, promovendo o crescimento em altura das mudas superior ao das bandejas de isopor, com cavidades de 6,2 e $12,0 \mathrm{~cm}$ e volumes de 35 e $70 \mathrm{~cm}^{3}$, respectivamente (Gomes et al., 1985).

Os tubetes, em uso para grande número de eucaliptos, não proporcionou crescimento satisfatório de mudas de Eucalyptus cloeziana e E. pyrocarpa (Henriques, 1987), sendo inadequado para Pinus taeda (Novaes, 1998).

Mesmo existindo controvérsias, as vantagens dos tubetes justificam a sua utilização nas empresas florestais que necessitam produzir grandes quantidades de mudas em menor tempo, com relativo baixo custo e no padrão de qualidade exigido, além do fato de a mecanização do processo de produção de mudas ser uma exigência econômica. O futuro da produção de mudas depende da utilização do tubete ou de alguma embalagem semelhante e, preferencialmente, que seja biodegradável (GOMES et al., 1985).

O objetivo deste trabalho foi o avaliar o crescimento de mudas de Eucalyptus grandis W. Hill ex Maiden, produzidas em diferentes tamanhos de tubetes e fertilização N-P-K.

\section{MATERIAL E MÉTODOS}

Este experimento foi instalado no Viveiro de Pesquisas em Propagação de Plantas Lenhosas do Departamento de Engenharia Florestal da Universidade Federal de Viçosa, Viçosa-MG, em novembro de 2000.

As sementes de Eucalyptus grandis foram coletadas e fornecidas pela CENIBRA - Celulose Nipo-Brasileira S.A. da APS SBA-01.

A semeadura foi efetuada diretamente nos tubetes cônicos de plástico rígido, colocando-se, em média, cinco sementes por embalagem. Aos 30 dias após a semeadura, foi efetuado um raleio, com o objetivo de eliminar as mudas excedentes em cada embalagem, deixando-se apenas uma, sendo esta a melhor e a mais central.
Os quatro tamanhos de tubetes, com 50, 110, 200 e $280 \mathrm{~cm}^{3}$ de volume, ficaram acondicionados em bandejas plásticas suspensas a $80 \mathrm{~cm}$ do solo.

O substrato usado foi a mistura de $80 \%$ de composto orgânico e de $20 \%$ de moinha de carvão, por ser recomendado na produção de mudas de Eucalyptus grandis em tubetes (Gomes et al., 1985).

O composto orgânico foi produzido a partir de esterco bovino ( $40 \%$ ) e de capim-gordura (60\%), e a moinha de carvão foi obtida da trituração do carvão de eucalipto, tendo sido utilizada somente a porção de granulometria entre 1 e $5 \mathrm{~mm}$.

A mistura do composto orgânico com a moinha de carvão foi expurgada com brometo de metila, aplicandose $20 \mathrm{ml} / \mathrm{m}^{2}$, tendo como objetivo a eliminação dos possíveis patógenos e das sementes indesejáveis (Gomes et al., 1978).

As fertilizações foram via água, sendo as doses aplicadas para cada metro cúbico do substrato, tendo como fontes o sulfato de amônio (0 e $600 \mathrm{~g}$ - N0 e N1), o superfosfato simples ( 0 e $5 \mathrm{~kg}$ - P0 e P1) e o cloreto de potássio ( 0 e $400 \mathrm{~g}$ - K0 e K1). As fontes foram moídas, dissolvidas em água e aplicadas ao substrato antes da semeadura, cujas análises apresentaram teores de fósforo $\left(845 \mathrm{mg} / \mathrm{dm}^{3}\right)$, de potássio $\left(1.365 \mathrm{mg} / \mathrm{dm}^{3}\right)$, de cálcio $\left(3,24 \mathrm{cmol} / \mathrm{dm}^{3}\right)$ e de magnésio $\left(2,74 \mathrm{cmol}_{\mathrm{c}} / \mathrm{dm}^{3}\right)$.

A presença e a ausência do $\mathrm{N}$, do $\mathrm{P}$ e do K, combinados entre si e com os quatro tamanhos de tubetes, constituíram os 32 tratamentos deste trabalho.

Os parâmetros utilizados nas avaliações dos resultados foram a altura da parte aérea $(\mathrm{H})$, o diâmetro do colo (DC), o peso de matéria seca total (PMST), o peso de matéria seca da parte aérea (PMSPA), o peso de matéria seca das raízes (PMSR), a relação entre a altura da parte aérea e o diâmetro do colo (RHDC), a relação entre a altura da parte aérea e o peso de matéria seca da parte aérea (RHPMSPA), a relação entre o peso de matéria seca da parte aérea e o peso de matéria seca das raízes (RPPAR) e o índice de qualidade de Dickson (IQD).

$\mathrm{A} \mathrm{H}$ foi determinada com uma régua milimetrada, a partir do nível do substrato até a ponta da última folha, e o DC foi determinado ao nível do substrato, por um paquímetro de precisão. As determinações do PMSPA e do PMSR foram efetuadas a partir do material seco em estufa a $75{ }^{\circ} \mathrm{C}$, por 72 horas. O PMST foi a soma dos pesos citados. As relações entre os parâmetros foram determinadas pela simples divisão.

R. Árvore, Viçosa-MG, v.27, n.2, p.113-127, 2003 
$O$ índice de qualidade de Dickson (IQD) foi determinado em função da $\mathrm{H}$, do DC, do PMSPA e do PMSR, por meio da seguinte fórmula:

$$
\mathrm{IQD}=\frac{\operatorname{PMST}(\mathrm{g})}{\mathrm{H}(\mathrm{cm}) / \mathrm{DC}(\mathrm{mm})+\operatorname{PMSPA}(\mathrm{g}) / \operatorname{PMSR}(\mathrm{g})}
$$

O delineamento experimental foi o de blocos casualizados, dispostos em um arranjo fatorial com 32 tratamentos e três repetições, sendo a parcela composta por 18 mudas. Em cada uma das três medições realizadas foram utilizadas seis mudas.

A H, o DC, o PMSPA e o PMSR foram determinados, utilizando as seis mudas destinadas para tal, aos 60, 90 e 120 dias após a semeadura.

\section{RESULTADOS E DISCUSSÃO}

Os resumos das análises de variâncias dos dados da H, do DC, da RHDC, do PMSPA, do PMSR, do PMST, da RHPMSPA, da RPPAR e do IQD das mudas de Eucalyptus grandis, avaliadas aos 60, 90 e 120 dias após a semeadura, estão no Quadro 1.
Os tamanhos dos tubetes promoveram crescimentos diferentes, em nível de $1 \%$ de probabilidade, para todos os parâmetros e idades. Este resultado foi o esperado, uma vez que o tubete de maior volume $\left(280 \mathrm{~cm}^{3}\right)$ ultrapassa cinco vezes o do menor $\left(50 \mathrm{~cm}^{3}\right)$.

O maior tubete disponibilizou mais nutrientes, uma vez que os pesos dos adubos foram adicionados em relação aos volumes do substrato, além de não limitar o crescimento das raízes.

Nos tubetes de maior volume, mesmo aos 120 dias, ainda existem disponibilidades de espaço e de nutrientes, o que permite a continuidade do crescimento das mudas.

Ainda considerando o Quadro 1, pode-se constatar que a adubação promoveu efeitos significativos (em nível de $1 \%$ de probabilidade) na idade de 60 dias, para todos os parâmetros analisados, menos para o PMSR, para a RPPAR e para o IQD.

Aos 90 dias os efeitos positivos das fertilizações somente foram significativos para o PMSPA, o PMST, a RHPMSPA e o IQD, e com 120 dias nenhum dos parâmetros sofreu efeitos significativos em função das fertilizações adicionadas.

Quadro 1 - Resumo da análise de variância das médias dos parâmetros de avaliação da qualidade de mudas de Eucalyptus grandis aos 60, 90 e 120 dias

Table 1 - Summary of the analysis of variance for the average parameters for evaluating the quality of Eucalyptus grandis seedlings at ages of 60, 90 and 120 days

\begin{tabular}{|c|c|c|c|c|c|c|c|c|c|c|}
\hline \multirow{2}{*}{ FV } & \multirow{2}{*}{ GL } & \multicolumn{9}{|c|}{ Quadrado Médio } \\
\hline & & $\mathrm{H}$ & $\mathrm{DC}$ & PMSPA & PMSR & PMST & RHDC & RHPMSPA & RPPAR & IQD \\
\hline \multicolumn{11}{|c|}{60 DIAS } \\
\hline Blocos & 2 & 1,51 & 0,0075 & 0,021 & 0,075 & 0,160 & 3,88 & 104,98 & 2,05 & 0,000576 \\
\hline Tubetes (T) & 3 & $555,25^{* *}$ & $3,3842 * *$ & $1,244 * *$ & $0,104 * *$ & $1,939^{* *}$ & $194,9171^{* *}$ & $3173,87^{* *}$ & $12,02 * *$ & $0,007968^{* *}$ \\
\hline Adubo (A) & 7 & $6,81 * *$ & $0,0054^{* *}$ & $0,018^{* *}$ & $0,006^{\mathrm{NS}}$ & $0,0408^{*}$ & $4,7601 * *$ & $80,16^{* *}$ & $0,10^{\mathrm{ns}}$ & $0,000105^{\mathrm{ns}}$ \\
\hline T X A & 21 & $5,79 * *$ & $0,0111^{* *}$ & $0,007 *$ & $0,004^{\mathrm{NS}}$ & $0,016^{\mathrm{ns}}$ & $4,7486^{\mathrm{ns}}$ & $16,72^{\mathrm{ns}}$ & $0,15^{\mathrm{ns}}$ & $0,000080^{\mathrm{ns}}$ \\
\hline $\mathrm{CV}_{\text {exp. }}(\%)$ & & 7,77 & 6,69 & 5,65 & 42,65 & 21,40 & 10,32 & 12,32 & 33,18 & 23,99 \\
\hline \multicolumn{11}{|c|}{90 DIAS } \\
\hline Blocos & 2 & 41,86 & 0,0059 & 0,027 & 0,141 & 0,254 & 12,3797 & 13,14 & 3,48 & 0,000252 \\
\hline Tubetes $(\mathrm{T})$ & 3 & $3193,08 * *$ & $0,0175^{*}$ & $15,673 * *$ & $1,491 * *$ & $26,403 * *$ & $241,8966^{* *}$ & $2262,90 * *$ & $3,71 * *$ & $0,041881^{* *}$ \\
\hline Adubo (A) & 7 & $24,88^{\mathrm{NS}}$ & $0,1055^{\mathrm{NS}}$ & $0,089^{*}$ & $0,012^{\mathrm{NS}}$ & $0,176^{*}$ & $31,3494^{\mathrm{NS}}$ & $23,69 *$ & $0,15^{\mathrm{ns}}$ & $0,000565^{*}$ \\
\hline T X A & 21 & 39,42 ** & $0,0916^{* *}$ & $0,076^{* *}$ & $0,006^{\mathrm{NS}}$ & $0,102 *$ & $55,4063 * *$ & $15,05^{\mathrm{ns}}$ & $0,33^{\mathrm{ns}}$ & $0,000522 *$ \\
\hline $\mathrm{CV}_{\text {exp. }}(\%)$ & & 12,77 & 6,09 & 14,05 & 19,35 & 12,87 & 12,60 & 11,62 & 17,78 & 19,30 \\
\hline \multicolumn{11}{|c|}{120 DIAS } \\
\hline Blocos & 2 & 3,20 & 0,2401 & 0,569 & 0,098 & 0,432 & 17,1743 & 48,54 & 2,22 & 0,003471 \\
\hline Tubetes (T) & 3 & $4945,30 * *$ & $53,478 * *$ & $60,764 * *$ & $6,819 * *$ & $107,526 * *$ & $1475,1060 * *$ & $2753,52 * *$ & $2,75^{* *}$ & $0,488613 * *$ \\
\hline Adubo (A) & 7 & $35,55^{\mathrm{NS}}$ & $0,0671^{\mathrm{NS}}$ & $0,141^{\mathrm{NS}}$ & $0,019^{\mathrm{NS}}$ & $0,205^{\mathrm{ns}}$ & $17,6152^{\mathrm{NS}}$ & $23,81^{\mathrm{ns}}$ & $0,09^{\mathrm{ns}}$ & $0,001885^{\text {ns }}$ \\
\hline T X A & 21 & $60,73^{* *}$ & $0,0807^{\mathrm{NS}}$ & $0,234^{\mathrm{NS}}$ & $0,030^{\mathrm{NS}}$ & $0,357 *$ & $14,7344^{\mathrm{NS}}$ & $16,01^{\mathrm{ns}}$ & $0,13^{\mathrm{ns}}$ & $0,001723^{\text {ns }}$ \\
\hline $\mathrm{CV}_{\text {exp. }}(\%)$ & & 10,89 & 7,90 & 17,78 & 17,51 & 14,20 & 23,88 & 18,54 & 17,68 & 16,54 \\
\hline
\end{tabular}

** F significativo a $1 \%$ de probabilidade, ${ }^{*} \mathrm{~F}$ significativo a $5 \%$ de probabilidade $\mathrm{e}^{\mathrm{ns}}$ não-significativo a $5 \%$ de probabilidade.

R. Árvore, Viçosa-MG, v.27, n.2, p.113-127, 2003 
À medida que as mudas ficam mais velhas, elas crescem e, conseqüentemente, as quantidades exigidas de nutrientes aumentam. Porém, sem considerar o tamanho do tubete, a disponibilidade nutricional não afetou os parâmetros analisados, uma vez que os níveis de fósforo $\left(845 \mathrm{mg} / \mathrm{dm}^{3}\right)$, de potássio $\left(1365 \mathrm{mg} / \mathrm{dm}^{3}\right)$, de cálcio $\left(3,24 \mathrm{cmol}_{\mathrm{c}} / \mathrm{dm}^{3}\right)$ e de magnésio $\left(2,74 \mathrm{cmol}_{\mathrm{c}} / \mathrm{dm}^{3}\right)$ no substrato, antes das adubações, já estavam bem altos e, possivelmente, muito além dos críticos exigidos para o crescimento.

Analisando o Quadro 2, pode-se constatar que as médias do crescimento em altura da parte aérea $(\mathrm{H})$ foram mais influenciadas pelos volumes dos tubetes e pelas idades das mudas do que pelas fertilizações.
Em cada idade, independentemente das fertilizações, as médias das alturas foram significativamente maiores pelo teste de Tukey, em nível de 5\% de probabilidade, à medida que se aumentou o volume dos tubetes, provavelmente devido às considerações de nutrição e espaço para crescimento radicular em maior volume de substrato.

Esses resultados foram semelhantes aos encontrados em alguns trabalhos de pesquisa, nos quais o pequeno volume da embalagem causou restrição ao crescimento do sistema radicular, provocando menor altura de mudas de Eucalyptus grandis, porém no campo esse efeito tendeu a desaparecer com o tempo (Barros et al., 1978).

Quadro 2 - Médias das alturas das mudas (H) de mudas de Eucalyptus grandis em diferentes idades, adubações e tamanhos de tubetes

Table 2 - Average of the Eucalyptus grandis seedling heights (H) at different ages (60, 90 and 120 days), fertilization and tubes sizes

\begin{tabular}{|c|c|c|c|c|c|c|}
\hline \multirow{2}{*}{$\begin{array}{l}\text { Idade } \\
\text { (dias) }\end{array}$} & \multirow{2}{*}{ Adubação } & \multicolumn{4}{|c|}{ Tubete } & \multirow{2}{*}{ Média } \\
\hline & & $\mathrm{A}\left(50 \mathrm{~cm}^{3}\right)$ & $\mathrm{B}\left(110 \mathrm{~cm}^{3}\right)$ & $\mathrm{C}\left(200 \mathrm{~cm}^{3}\right)$ & $\mathrm{D}\left(280 \mathrm{~cm}^{3}\right)$ & \\
\hline \multirow{9}{*}{60} & N0-P0-K0 & $7,90 \mathrm{Da}$ & $12,69 \mathrm{Cab}$ & $14,67 \mathrm{Bab}$ & $21,58 \mathrm{Aab}$ & 14,21 \\
\hline & N0-P1-K0 & 8,32 Da & $13,39 \mathrm{Cab}$ & $15,85 \mathrm{Bab}$ & $23,24 \mathrm{Aa}$ & 15,20 \\
\hline & N0-P0-K1 & $8,22 \mathrm{Da}$ & $12,61 \mathrm{Cab}$ & $16,63 \mathrm{Ba}$ & $20,46 \mathrm{Abc}$ & 14,48 \\
\hline & N0-P1-K1 & $8,11 \mathrm{Da}$ & $11,68 \mathrm{Cb}$ & $14,48 \mathrm{Bab}$ & $19,09 \mathrm{Abc}$ & 13,34 \\
\hline & N1-P0-K0 & 7,73 Ca & $13,18 \mathrm{Bab}$ & $14,89 \mathrm{Bab}$ & $19,89 \mathrm{Abc}$ & 13,92 \\
\hline & N1-P1-K0 & $6,85 \mathrm{Ca}$ & $13,65 \mathrm{Bab}$ & $15,06 \mathrm{Bab}$ & $19,93 \mathrm{Abc}$ & 13,87 \\
\hline & N1-P0-K1 & $8,45 \mathrm{Ca}$ & $14,61 \mathrm{Ba}$ & $14,78 \mathrm{Bab}$ & $18,03 \mathrm{Ac}$ & 13,97 \\
\hline & N1-P1-K1 & $8,41 \mathrm{Ba}$ & $13,60 \mathrm{Aab}$ & $13,80 \mathrm{Ab}$ & $14,79 \mathrm{Ad}$ & 12,65 \\
\hline & Média & 8,00 & 13,18 & 15,02 & 19,63 & \\
\hline \multirow{9}{*}{90} & N0-P0-K0 & $17,34 \mathrm{Ca}$ & $25,37 \mathrm{Ba}$ & 27,93 Bbc & $49,05 \mathrm{Aa}$ & 29,92 \\
\hline & N0-P1-K0 & $18,23 \mathrm{Ca}$ & $24,31 \mathrm{Ca}$ & 32,53 Babc & $48,44 \mathrm{Aa}$ & 30,88 \\
\hline & N0-P0-K1 & $16,47 \mathrm{Ca}$ & $25,21 \mathrm{Ba}$ & $39,03 \mathrm{Aa}$ & 45,11 Aabc & 31,46 \\
\hline & N0-P1-K1 & $16,13 \mathrm{Ca}$ & $24,91 \mathrm{Ba}$ & $26,27 \mathrm{Bc}$ & 44,28 Aabc & 27,90 \\
\hline & $\mathrm{N} 1-\mathrm{P} 0-\mathrm{K} 0$ & $15,01 \mathrm{Da}$ & $26,99 \mathrm{Ca}$ & $37,06 \mathrm{Bab}$ & 46,88 Aab & 31,49 \\
\hline & N1-P1-K0 & $13,89 \mathrm{Ca}$ & $24,91 \mathrm{Ba}$ & $38,51 \mathrm{Aa}$ & 40,69 Aabc & 29,50 \\
\hline & N1-P0-K1 & $17,77 \mathrm{Ca}$ & $27,37 \mathrm{Ba}$ & $31,25 \mathrm{Babc}$ & $38,35 \mathrm{Abc}$ & 28,69 \\
\hline & N1-P1-K1 & $16,61 \mathrm{Ca}$ & $26,43 \mathrm{Ba}$ & 32,96 Aabc & $36,45 \mathrm{Ac}$ & 28,11 \\
\hline & Média & 16,43 & 25,69 & 33,19 & 43,66 & \\
\hline \multirow{9}{*}{120} & N0-P0-K0 & $21,86 \mathrm{Ca}$ & $29,50 \mathrm{Ba}$ & $36,26 \mathrm{Bc}$ & $61,66 \mathrm{Aa}$ & 37,32 \\
\hline & N0-P1-K0 & $24,06 \mathrm{Da}$ & $33,61 \mathrm{Ca}$ & 44,69 Babc & $61,00 \mathrm{Aab}$ & 40,84 \\
\hline & N0-P0-K1 & $23,28 \mathrm{Ca}$ & $32,92 \mathrm{Ba}$ & $52,42 \mathrm{Aa}$ & 54,61 Aabd & 40,81 \\
\hline & N0-P1-K1 & $19,04 \mathrm{Da}$ & $35,37 \mathrm{Ca}$ & 43,64 Babc & 57,51 Aabd & 38,89 \\
\hline & N1-P0-K0 & $19,55 \mathrm{Da}$ & $33,96 \mathrm{Ca}$ & $48,86 \mathrm{Bab}$ & 58,79 Aabc & 40,29 \\
\hline & N1-P1-K0 & $20,38 \mathrm{Ca}$ & $32,60 \mathrm{Ba}$ & $50,92 \mathrm{Aa}$ & $50,41 \mathrm{Abcd}$ & 38,58 \\
\hline & N1-P0-K1 & $22,40 \mathrm{Ca}$ & $36,71 \mathrm{Ba}$ & $38,62 \mathrm{Bbc}$ & 48,95 Acd & 36,67 \\
\hline & N1-P1-K1 & $22,39 \mathrm{Ca}$ & $35,68 \mathrm{Ba}$ & $42,45 \mathrm{Abac}$ & $47,15 \mathrm{Ad}$ & 36,92 \\
\hline & Média & 21,62 & 33,79 & 44,73 & 55,01 & \\
\hline
\end{tabular}

Em cada idade e cada adubação (linha), médias seguidas de pelo menos uma mesma letra maiúscula não diferem entre si pelo teste de Tukey ( $\mathrm{P}>0,05)$. Em cada idade e cada tubete (coluna), médias seguidas de pelo menos uma mesma letra minúscula não diferem entre si pelo teste de Tukey (P>0,05). 
O crescimento em altura de mudas de Cryptomeria japonica está diretamente relacionado com o volume do tubete (Santos et al., 2000), estando também relacionado para mudas de Eucalyptus grandis, produzidas em sacolas plásticas (Venturim, 1978).

Resultados também semelhantes foram encontrados com muda de Eucalyptus grandis, E. camaldulensis e E. cloeziana, de onde se conclui ainda que a espécie mais sensível à restrição do sistema radicular foi o Eucalyptus grandis (Reis, et al., 1989).

As dimensões dos recipientes e os conseqüentes volumes influenciam a disponibilidade de nutrientes e água (Böhm, 1979), devendo ser ressaltado que maior volume promove a arquitetura do sistema radicular semelhante à de mudas provenientes de semeadura direta no campo (Parviainen,1976), apesar de as grandes dimensões provocarem gastos desnecessários, aumentando a área do viveiro, os custos de transporte e a distribuição das mudas no campo (Carneiro, 1995), acarretando, em geral, maiores custos de produção (Gonzalez, 1988; Gomes et al., 1990) e de plantio.

A maior altura do tubete correspondeu ao de maior volume, sendo essa de $19 \mathrm{~cm}$ (Quadro 2), uma vez que a altura e o diâmetro dos recipientes variam com as características de cada espécie (Ferreira, 1985; Carneiro, 1987; Gomes et al., 1990), mas em geral a altura da embalagem foi mais importante do que o seu diâmetro para o crescimento de mudas de diferentes espécies florestais, inclusive para o Eucalyptus grandis (Gomes et al., 1980, 1981, 1990).

No tubete de menor tamanho as adições de fertilizantes não promoveram diferenças significantes, em nível de $5 \%$ de probabilidade, pelo teste de Tukey, nas médias de alturas. Talvez este fato se deva à restrição ao crescimento do sistema radicular radicular, devido ao baixo volume de substrato e, conseqüentemente, ao fornecimento de quantidades de nutrientes aquém das exigidas pelas mudas, e para compensar as perdas, principalmente por lixiviação, com resultados semelhantes aos obtidos por outros pesquisadores (Neves et al., 1990; Carneiro, 1995).

As diferenças de alturas aumentaram à medida que os tubetes eram maiores, mas sem a definição de tendência de crescimento para essa ou aquela combinação dos elementos nutricionais adicionados.

Independentemente das idades, as maiores médias de alturas das mudas foram as obtidas nos tratamentos em que somente o fósforo estava presente, sendo tais resultados semelhantes aos relatados por Rocha \& Braga (1982).

As menores médias foram conseguidas na presença dos três elementos ou nos tratamentos em que houve adição do nitrogênio, podendo ser explicado pelas doses, possivelmente elevadas, desse elemento (Gomes \& Couto, 1983).

Apesar de ainda existir controvérsias sobre o tamanho de mudas, considera-se que elas poderiam estar prontas para serem plantadas com alturas variando de 20 a $35 \mathrm{~cm}$.

Aos 60 dias após a semeadura somente algumas das mudas produzidas no maior tubete utilizado estavam prontas, com alturas no padrão definido para o plantio.

Nessa idade as mudas ainda não estão endurecidas o suficiente para serem plantadas e resistirem às condições adversas que poderiam encontrar no campo, além de o sistema radicular se encontrar pouco desenvolvido, não formando um torrão bem agregado ao substrato, condição relatada como indispensável para o transporte das mudas para o campo (Gomes et al., 1991), principalmente quando produzidas em tubetes.

Com 90 dias de idade as embalagens intermediárias proporcionaram mudas com as alturas no intervalo desejado, podendo ser indicado o tubete de volume de $110 \mathrm{~cm}^{3}$.

Com 120 dias de idade, independentemente do tamanho do tubete e da fertilização, todas as mudas poderiam ser plantadas, considerando que não diferiram estatisticamente, mas principalmente os dois maiores tubetes proporcionaram mudas com alturas muito além das tecnicamente desejadas, podendo ocasionar a menor sobrevivência após plantio, além do maior custo que as maiores embalagens causam para todo o processo de produção, transporte, distribuição e plantio das mudas

As médias dos diâmetros dos colos (Quadro 3) seguem a tendência de crescimento semelhante à das alturas, devendo ser ressaltado que, independentemente da idade, as maiores médias foram também obtidas nos maiores tubetes, mas somente sendo diferentes pelo teste de Tukey, em nível de 5\% de probabilidade, na idade de 120 dias. Resultados semelhantes foram também obtidos para Cryptomeria japonica (Santos et al., 2000).

De modo geral, a fertilização não promoveu diferenças de crescimento para esse parâmetro, a não ser 
pequenas variações nas mudas produzidas nos tubetes de maiores volumes, sendo os piores resultados obtidos na presença dos três elementos.

Quando são considerados o intervalo de altura para o plantio e a economicidade na produção, são escolhidos os tubetes de menores dimensões, sendo mais indicado o de volume de $110 \mathrm{~cm}^{3}$. Resultado semelhante foi obtido onde esse volume foi também o indicado para produção de mudas de Cryptomeria japonica (Santos et al., 2000).

Quando se analisa o Quadro 4, constata-se que tanto os tubetes de maiores volumes quanto os de menores promoveram maiores médias da relação altura/diâmetro do colo, sendo os dois de tamanhos intermediários os que melhor se adequaram, uma vez que quanto menor for o valor dessa relação maior será a capacidade de as mudas sobreviverem e se estabelecerem no campo (Carneiro, 1983).

Considerando que os tubetes de tamanhos intermediárias foram os melhores e que não houve diferenças estatísticas entre eles, o de volume de $110 \mathrm{~cm}^{3}$ seria o indicado.

Essa relação exprime um equilíbrio de crescimento, relacionando esses dois parâmetros em apenas um índice (Carneiro, 1995), sendo considerado preciso por indicar o quanto delgada está a muda (Johnson \& Cline, 1991).

No Quadro 5 verifica-se que à medida que o volume da embalagem aumentou houve aumento do peso de matéria seca da parte aérea (PMSPA) das mudas, semelhante

Quadro 3 - Médias dos diâmetros do coleto (DC) de mudas de Eucalyptus grandis em diferentes idades, adubações e tamanhos de tubetes

Table 3 - Averages of the root collar diameter (DC) of Eucalyptus grandis seedlings at different ages (60, 90 and 120 days), fertilization and tube sizes

\begin{tabular}{|c|c|c|c|c|c|c|}
\hline \multirow{2}{*}{$\begin{array}{l}\text { Idade } \\
\text { (dias) }\end{array}$} & \multirow{2}{*}{ Adubação } & \multicolumn{4}{|c|}{ Tubete } & \multirow{2}{*}{ Média } \\
\hline & & $\mathrm{A}\left(50 \mathrm{~cm}^{3}\right)$ & $\mathrm{B}\left(110 \mathrm{~cm}^{3}\right)$ & $\mathrm{C}\left(200 \mathrm{~cm}^{3}\right)$ & $\mathrm{D}\left(280 \mathrm{~cm}^{3}\right)$ & \\
\hline \multirow{9}{*}{60} & N0-P0-K0 & 0,392 & 0,881 & 1,005 & 1,398 & 0,919 \\
\hline & N0-P1-K0 & 0,407 & 0,860 & 1,163 & 1,198 & 0,907 \\
\hline & N0-P0-K1 & 0,452 & 0,833 & 1,235 & 1,261 & 0,945 \\
\hline & N0-P1-K1 & 0,412 & 0,865 & 1,153 & 1,314 & 0,936 \\
\hline & $\mathrm{N} 1-\mathrm{P} 0-\mathrm{K} 0$ & 0,392 & 0,905 & 1,079 & 1,237 & 0,903 \\
\hline & N1-P1-K0 & 0,367 & 0,865 & 1,129 & 1,270 & 0,908 \\
\hline & N1-P0-K1 & 0,400 & 0,901 & 1,161 & 1,158 & 0,905 \\
\hline & N1-P1-K1 & 0,379 & 0,875 & 1,115 & 1,138 & 0,877 \\
\hline & Média & $0,400 \mathrm{D}$ & $0,873 \mathrm{C}$ & $1,130 \mathrm{~B}$ & $1,247 \mathrm{~A}$ & \\
\hline \multirow{9}{*}{90} & N0-P0-K0 & $0,639 \mathrm{Ca}$ & $1,371 \mathrm{Ba}$ & $1,849 \mathrm{Aa}$ & $1,347 \mathrm{Bc}$ & 1,302 \\
\hline & N0-P1-K0 & 0,681 Da & $1,320 \mathrm{Ca}$ & $1,779 \mathrm{Ba}$ & $1,985 \mathrm{Aa}$ & 1,441 \\
\hline & N0-P0-K1 & $0,698 \mathrm{Ca}$ & $1,363 \mathrm{Ba}$ & $1,816 \mathrm{Aa}$ & $1,905 \mathrm{Aab}$ & 1,446 \\
\hline & N0-P1-K1 & $0,640 \mathrm{Da}$ & $1,357 \mathrm{Ca}$ & $1,671 \mathrm{Ba}$ & $1,821 \mathrm{Aab}$ & 1,372 \\
\hline & $\mathrm{N} 1-\mathrm{P} 0-\mathrm{K} 0$ & $0,612 \mathrm{Da}$ & $1,437 \mathrm{Ca}$ & $1,703 \mathrm{Ba}$ & 1,911 Aab & 1,416 \\
\hline & N1-P1-K0 & $0,607 \mathrm{Ca}$ & $1,289 \mathrm{Ba}$ & $1,777 \mathrm{Aa}$ & $1,872 \mathrm{Aab}$ & 1,386 \\
\hline & N1-P0-K1 & $0,656 \mathrm{Ca}$ & $1,365 \mathrm{Ba}$ & 1,669 Aa & 1,797 Aab & 1,372 \\
\hline & N1-P1-K1 & $0,600 \mathrm{Da}$ & $1,386 \mathrm{Ba}$ & $1,955 \mathrm{Aa}$ & $1,699 \mathrm{Ab}$ & 1,410 \\
\hline & Média & $0,642 \mathrm{D}$ & $1,361 \mathrm{C}$ & $1,777 \mathrm{~B}$ & $1,792 \mathrm{~A}$ & \\
\hline \multirow{9}{*}{120} & N0-P0-K0 & 0,855 & 2,899 & 3,414 & 4,714 & 2,971 \\
\hline & N0-P1-K0 & 0,783 & 2,767 & 3,694 & 4,027 & 2,818 \\
\hline & N0-P0-K1 & 0,783 & 2,868 & 3,775 & 4,001 & 2,857 \\
\hline & N0-P1-K1 & 0,815 & 2,901 & 3,589 & 4,156 & 2,865 \\
\hline & $\mathrm{N} 1-\mathrm{P} 0-\mathrm{K} 0$ & 0,767 & 2,979 & 3,735 & 4,079 & 2,890 \\
\hline & N1-P1-K0 & 0,793 & 3,131 & 3,933 & 4,000 & 2,964 \\
\hline & N1-P0-K1 & 0,841 & 3,004 & 3,892 & 4,297 & 3,009 \\
\hline & N1-P1-K1 & 0,724 & 2,805 & 3,697 & 4,008 & 2,809 \\
\hline & Média & $0,795 \mathrm{D}$ & $2,919 \mathrm{C}$ & $3,716 \mathrm{~B}$ & $4,160 \mathrm{~A}$ & \\
\hline
\end{tabular}

Em cada idade e cada adubação (linha), médias seguidas de pelo menos uma mesma letra maiúscula não diferem entre si pelo teste de Tukey (P>0,05). Em cada idade e cada tubete (coluna), médias seguidas de pelo menos uma mesma letra minúscula não diferem entre si pelo teste de Tukey (P>0,05). 
aos resultados obtidos para Cryptomeria japonica (Santos et al., 2000), podendo ser explicado da mesma maneira que o foi para a altura e para o diâmetro, uma vez que os mesmos fatores que exercem influências no crescimento da parte aérea também atuam sobre o peso de matéria seca (Carneiro, 1981).

As fertilizações não influenciaram a produção de matéria seca da parte aérea, nos dois menores tubetes, mas para os dois maiores as diferenças foram significativas na idade de 60 dias e aos 90 somente o maior promoveu produções significativas.

Analisando as médias dos pesos de matéria seca das raízes (Quadro 6), observa-se que aos 60 dias houve diferenças significativas, sendo maior nos tubetes mais volumosos, o que mostra a tendência para a maior produção no tubete de $200 \mathrm{~cm}^{3}$.

Aos 90 dias as maiores produções foram a favor do tubete de maior volume, independentemente das fertilizações. Aos 120 dias os resultados foram semelhantes.

Resultados semelhantes foram obtidos em mudas de Cryptomeria japonica, cuja maior massa seca das raízes foi relacionada com o volume do tubete (Santos et al., 2000), devendo ser ressaltado que os de maiores dimensões produziram mudas de Pinus taeda e de Pinus echinata também com mais raízes (Brissette, 1984; Carneiro,1985).

Independentemente das idades e das fertilizações, as médias da produção de matéria seca total (PMST) das

Quadro 4 - Médias da relação altura/diâmetro do coleto (RHDC) de mudas de Eucalyptus grandis em diferentes idades, adubações e tamanhos de tubetes.

Table 4 - Average of the root colar diameter (DC) of Eucalyptus grandis seedlings at different ages (60, 90 and 120 days), fertilization and tube sizes

\begin{tabular}{|c|c|c|c|c|c|c|}
\hline \multirow{2}{*}{$\begin{array}{l}\text { Idade } \\
\text { (dias) }\end{array}$} & \multirow{2}{*}{ Adubação } & \multicolumn{4}{|c|}{ Tubete } & \multirow{2}{*}{ Média } \\
\hline & & $\mathrm{A}\left(50 \mathrm{~cm}^{3}\right)$ & $\mathrm{B}\left(110 \mathrm{~cm}^{3}\right)$ & $\mathrm{C}\left(200 \mathrm{~cm}^{3}\right)$ & $\mathrm{D}\left(280 \mathrm{~cm}^{3}\right)$ & \\
\hline \multirow{9}{*}{60} & N0-P0-K0 & 20,18 & 14,42 & 14,88 & 15,41 & 16,22 \\
\hline & N0-P1-K0 & 20,48 & 15,56 & 13,69 & 19,43 & 17,29 \\
\hline & N0-P0-K1 & 18,21 & 15,15 & 13,49 & 16,23 & 15,77 \\
\hline & N0-P1-K1 & 19,78 & 13,52 & 12,55 & 14,56 & 15,10 \\
\hline & N1-P0-K0 & 19,91 & 14,57 & 13,88 & 16,13 & 16,12 \\
\hline & N1-P1-K0 & 18,75 & 15,79 & 13,37 & 15,74 & 15,91 \\
\hline & N1-P0-K1 & 21,15 & 16,22 & 12,81 & 15,61 & 15,80 \\
\hline & N1-P1-K1 & 22,23 & 15,59 & 12,40 & 13,01 & 15,81 \\
\hline & Média & $20,09 \mathrm{~A}$ & $15,10 \mathrm{~B}$ & $13,39 \mathrm{C}$ & $15,77 \mathrm{~B}$ & \\
\hline \multirow{9}{*}{90} & N0-P0-K0 & $27,06 \mathrm{Ba}$ & $18,52 \mathrm{Ca}$ & $15,11 \mathrm{Cb}$ & $36,62 \mathrm{Aa}$ & 24,33 \\
\hline & N0-P1-K0 & $26,91 \mathrm{Aa}$ & $18,61 \mathrm{Ba}$ & $18,38 \mathrm{Bb}$ & $24,45 \mathrm{Ab}$ & 22,09 \\
\hline & N0-P0-K1 & $23,71 \mathrm{Aa}$ & $18,51 \mathrm{Ba}$ & $21,54 \mathrm{ABb}$ & $23,71 \mathrm{Ab}$ & 21,88 \\
\hline & N0-P1-K1 & $25,23 \mathrm{Aa}$ & $18,40 \mathrm{Ba}$ & $15,71 \mathrm{Bb}$ & $24,45 \mathrm{Ab}$ & 20,91 \\
\hline & $\mathrm{N} 1-\mathrm{P} 0-\mathrm{K} 0$ & $24,56 \mathrm{Aa}$ & $18,78 \mathrm{Ba}$ & $21,73 \mathrm{ABb}$ & $24,76 \mathrm{Ab}$ & 22,46 \\
\hline & N1-P1-K0 & $23,00 \mathrm{Aa}$ & $19,38 \mathrm{Aa}$ & $21,84 \mathrm{Ab}$ & $21,69 \mathrm{Ab}$ & 21,48 \\
\hline & N1-P0-K1 & $27,12 \mathrm{Aa}$ & $20,17 \mathrm{Ba}$ & $18,77 \mathrm{Bb}$ & $21,27 \mathrm{Bb}$ & 21,83 \\
\hline & N1-P1-K1 & $27,63 \mathrm{Ba}$ & $19,17 \mathrm{Ca}$ & $16,86 \mathrm{Bb}$ & $21,52 \mathrm{Cb}$ & 21,29 \\
\hline & Média & $25,65 \mathrm{~A}$ & $18,94 \mathrm{~B}$ & $18,72 \mathrm{~B}$ & $24,81 \mathrm{~A}$ & \\
\hline \multirow{9}{*}{120} & N0-P0-K0 & 25,57 & 10,20 & 10,58 & 13,15 & 14,87 \\
\hline & N0-P1-K0 & 30,83 & 12,14 & 12,10 & 15,18 & 17,56 \\
\hline & N0-P0-K1 & 29,84 & 11,49 & 13,89 & 13,66 & 17,22 \\
\hline & N0-P1-K1 & 23,38 & 12,22 & 12,16 & 13,87 & 15,41 \\
\hline & $\mathrm{N} 1-\mathrm{P} 0-\mathrm{K} 0$ & 25,52 & 11,41 & 13,25 & 14,51 & 16,17 \\
\hline & N1-P1-K0 & 25,75 & 10,46 & 12,99 & 12,64 & 15,46 \\
\hline & N1-P0-K1 & 26,63 & 12,22 & 9,90 & 11,40 & 15,04 \\
\hline & N1-P1-K1 & 35,90 & 12,71 & 11,47 & 11,77 & 17,96 \\
\hline & Média & $27,92 \mathrm{~A}$ & $11,61 \mathrm{~B}$ & $12,04 \mathrm{~B}$ & $13,27 \mathrm{~A}$ & \\
\hline
\end{tabular}

Em cada idade e cada adubação (linha), médias seguidas de pelo menos uma mesma letra maiúscula não diferem entre si pelo teste de Tukey (P>0,05). Em cada idade e cada tubete (coluna), médias seguidas de pelo menos uma mesma letra minúscula não diferem entre si pelo teste de Tukey $(\mathrm{P}>0,05)$.

R. Árvore, Viçosa-MG, v.27, n.2, p.113-127, 2003 
mudas foram significativamente superiores, em nível de $5 \%$ de probabilidade, à medida que se aumentou o volume dos tubetes, como pode ser observado no Quadro 7. Resultados semelhantes foram observados quando se analisou o crescimento em altura, concordando também com outros resultados de pesquisa cujos fatores que influenciaram o crescimento em altura de mudas de Pinus taeda atuaram sobre o peso de matéria seca (Carneiro, 1981)

Em mudas de Pinus caribaea var. hondurensis, Tabebuia serratifolia, Copaifera langsdorffii e Piptadenia (Anadenanthera) peregrina, também existe uma relação direta entre o tamanho do recipiente e o ganho em massa seca das mudas (Gomes et al., 1980, 1990).
Aos 120 dias após a semeadura a diferença de produção de matéria seca foi significativamente mais elevada no tubete de maior volume, o que pode ser explicado pela restrição ao crescimento imposta nos tubetes menores, como aconteceu para a altura das mudas e para o peso de matéria seca das raízes.

Os tubetes pequenos podem restringir o crescimento do sistema radicular, não sendo indicados para produção de mudas, como observado também para mudas de Eucalyptus camaldulensis, E. grandis e E. cloeziana por REIS et al. (1989), podendo causar pequeno crescimento no viveiro, mas recuperando o crescimento em altura de Eucalyptus grandis no campo (Barros et al., 1978).

Quadro 5 - Médias do peso de matéria seca da parte aérea (PMSPA) de mudas de Eucalyptus grandis em diferentes idades, adubações e tamanhos de tubetes

Table 5 - Averages of shoot dry matter weight (PMSPA) of Eucalyptus grandis seedlings different at ages (60, 90 and 120 days), fertilization and tube sizes

\begin{tabular}{|c|c|c|c|c|c|c|}
\hline \multirow{2}{*}{$\begin{array}{l}\text { Idade } \\
\text { (dias) }\end{array}$} & \multirow{2}{*}{ Adubação } & \multicolumn{4}{|c|}{ Tubete } & \multirow{2}{*}{ Média } \\
\hline & & $\mathrm{A}\left(50 \mathrm{~cm}^{3}\right)$ & $\mathrm{B}\left(110 \mathrm{~cm}^{3}\right)$ & $\mathrm{C}\left(200 \mathrm{~cm}^{3}\right)$ & $\mathrm{D}\left(280 \mathrm{~cm}^{3}\right)$ & \\
\hline \multirow{9}{*}{60} & N0-P0-K0 & $0,160 \mathrm{Da}$ & $0,321 \mathrm{Ca}$ & $0,602 \mathrm{Ba}$ & $0,825 \mathrm{Aa}$ & 0,477 \\
\hline & N0-P1-K0 & $0,153 \mathrm{Da}$ & $0,298 \mathrm{Ca}$ & $0,484 \mathrm{Bab}$ & $0,609 \mathrm{Abc}$ & 0,386 \\
\hline & N0-P0-K1 & $0,175 \mathrm{Ca}$ & $0,306 \mathrm{Ba}$ & $0,601 \mathrm{Aa}$ & 0,666 Aabc & 0,437 \\
\hline & N0-P1-K1 & $0,152 \mathrm{Da}$ & $0,267 \mathrm{Ca}$ & $0,455 \mathrm{Bab}$ & $0,693 \mathrm{Aab}$ & 0,392 \\
\hline & $\mathrm{N} 1-\mathrm{P} 0-\mathrm{K} 0$ & $0,139 \mathrm{Da}$ & $0,287 \mathrm{Ca}$ & $0,431 \mathrm{Bb}$ & $0,677 \mathrm{Aab}$ & 0,384 \\
\hline & N1-P1-K0 & $0,129 \mathrm{Da}$ & $0,304 \mathrm{Ca}$ & $0,555 \mathrm{Bab}$ & $0,699 \mathrm{Aab}$ & 0,422 \\
\hline & N1-P0-K1 & $0,157 \mathrm{Da}$ & $0,336 \mathrm{Ca}$ & $0,489 \mathrm{Bab}$ & $0,681 \mathrm{Aab}$ & 0,416 \\
\hline & N1-P1-K1 & $0,145 \mathrm{Ca}$ & $0,300 \mathrm{Ba}$ & $0,444 \mathrm{Aab}$ & $0,507 \mathrm{Ac}$ & 0,349 \\
\hline & Média & 0,151 & 0,302 & 0,508 & 0,670 & \\
\hline \multirow{9}{*}{90} & N0-P0-K0 & $0,430 \mathrm{Da}$ & $0,894 \mathrm{Ca}$ & $1,652 \mathrm{Ba}$ & $2,641 \mathrm{Aa}$ & 1,404 \\
\hline & N0-P1-K0 & $0,463 \mathrm{Ca}$ & $0,839 \mathrm{Ba}$ & $1,819 \mathrm{Aa}$ & $1,996 \mathrm{Abc}$ & 1,279 \\
\hline & N0-P0-K1 & $0,485 \mathrm{Da}$ & $0,801 \mathrm{Ca}$ & $1,954 \mathrm{Ba}$ & $2,368 \mathrm{Aab}$ & 1,402 \\
\hline & N0-P1-K1 & $0,396 \mathrm{Da}$ & $0,888 \mathrm{Ca}$ & $1,675 \mathrm{Ba}$ & $2,257 \mathrm{Aab}$ & 1,304 \\
\hline & $\mathrm{N} 1-\mathrm{P} 0-\mathrm{K} 0$ & $0,360 \mathrm{Da}$ & $0,893 \mathrm{Ca}$ & $1,630 \mathrm{Ba}$ & $2,024 \mathrm{Abc}$ & 1,227 \\
\hline & N1-P1-K0 & $0,313 \mathrm{Da}$ & $0,820 \mathrm{Ca}$ & $1,763 \mathrm{Ba}$ & $2,441 \mathrm{Aab}$ & 1,334 \\
\hline & N1-P0-K1 & $0,463 \mathrm{Da}$ & $0,987 \mathrm{Ca}$ & $1,725 \mathrm{Ba}$ & 2,187 Aabc & 1,341 \\
\hline & N1-P1-K1 & $0,409 \mathrm{Ca}$ & $0,897 \mathrm{Ba}$ & $1,575 \mathrm{Aa}$ & $1,718 \mathrm{Ac}$ & 1,150 \\
\hline & Média & 0,415 & 0,877 & 1,724 & 2,204 & \\
\hline \multirow{9}{*}{120} & N0-P0-K0 & 0,656 & 1,523 & 2,642 & 5,017 & 2,460 \\
\hline & N0-P1-K0 & 0,533 & 1,414 & 2,996 & 4,184 & 2,282 \\
\hline & N0-P0-K1 & 0,639 & 1,565 & 3,217 & 4,311 & 2,433 \\
\hline & N0-P1-K1 & 0,546 & 1,577 & 2,517 & 4,508 & 2,287 \\
\hline & $\mathrm{N} 1-\mathrm{P} 0-\mathrm{K} 0$ & 0,575 & 1,439 & 2,841 & 3,960 & 2,204 \\
\hline & N1-P1-K0 & 0,526 & 1,601 & 2,991 & 4,429 & 2,387 \\
\hline & N1-P0-K1 & 0,678 & 1,529 & 3,279 & 3,820 & 2,327 \\
\hline & $\mathrm{N} 1-\mathrm{P} 1-\mathrm{K} 1$ & 0,647 & 1,473 & 2,916 & 3,560 & 2,149 \\
\hline & Média & $0,600 \mathrm{D}$ & $1,515 \mathrm{C}$ & $2,925 \mathrm{~B}$ & $4,224 \mathrm{~A}$ & \\
\hline
\end{tabular}

Em cada idade e cada adubação (linha), médias seguidas de pelo menos uma mesma letra maiúscula não diferem entre si pelo teste de Tukey ( $\mathrm{P}>0,05)$. Em cada idade e cada tubete (coluna), médias seguidas de pelo menos uma mesma letra minúscula não diferem entre si pelo teste de Tukey ( $\mathrm{P}>0,05)$. 
Quando são considerados os aspectos técnico-econômicos, as embalagens de menores dimensões normalmente são as mais indicadas para algumas espécies florestais.

As combinações dos elementos $\mathrm{N}, \mathrm{P}$ e $\mathrm{K}$ não promoveram diferenças significativas para produção de matéria seca, com exceção da idade de 60 dias, mas com diferenças muito pequenas.

Mesmo assim pode-se verificar a tendência de menor produção de matéria seca onde os três elementos estavam presentes ou nos tratamentos em que houve adição do nitrogênio, o que pode ser explicado pelas doses elevadas deste elemento (Gomes \& Couto, 1983).
A relação altura/peso de matéria seca da parte aérea teve comportamento similar aos obtidos para altura e produção de matéria seca (Quadro 8).

$\mathrm{O}$ volume dos tubetes e a idade das mudas influenciaram essa relação, o que afeta consideravelmente o crescimento em altura e a produção de matéria seca, exprimindo o quanto endurecida está a muda. Quanto menor for esse valor mais lenificada será a muda e maior a sua capacidade de sobrevivência.

Como um índice de qualidade esta relação poderá ser de grande valia, podendo ser utilizada principalmente no que se refere ao potencial de sobrevivência no campo,

Quadro 6 - Médias do peso de matéria seca da raiz (PMSR) de mudas de Eucalyptus grandis em diferentes idades, adubações e tamanhos de tubetes

Table 6 -Averages of root dry matter weight (TDMW) of Eucalyptus grandis seedlings at different ages (60, 90 and 120 days), fertilization and tube sizes

\begin{tabular}{|c|c|c|c|c|c|c|}
\hline \multirow{2}{*}{$\begin{array}{l}\text { Idade } \\
\text { (dias) }\end{array}$} & \multirow{2}{*}{ Adubação } & \multicolumn{4}{|c|}{ Tubete } & \multirow{2}{*}{ Média } \\
\hline & & $\mathrm{A}\left(50 \mathrm{~cm}^{3}\right)$ & $\mathrm{B}\left(110 \mathrm{~cm}^{3}\right)$ & $\mathrm{C}\left(200 \mathrm{~cm}^{3}\right)$ & $\mathrm{D}\left(280 \mathrm{~cm}^{3}\right)$ & \\
\hline \multirow{9}{*}{60} & N0-P0-K0 & $0,177 \mathrm{Da}$ & 0,222 & 0,337 & 0,333 & 0,267 \\
\hline & N0-P1-K0 & $0,187 \mathrm{Ba}$ & 0,192 & 0,397 & 0,234 & 0,252 \\
\hline & N0-P0-K1 & $0,171 \mathrm{Ca}$ & 0,247 & 0,325 & 0,236 & 0,245 \\
\hline & N0-P1-K1 & $0,151 \mathrm{Ca}$ & 0,186 & 0,324 & 0,272 & 0,233 \\
\hline & $\mathrm{N} 1-\mathrm{P} 0-\mathrm{K} 0$ & $0,153 \mathrm{Ca}$ & 0,196 & 0,221 & 0,269 & 0,210 \\
\hline & N1-P1-K0 & $0,124 \mathrm{Ca}$ & 0,167 & 0,343 & 0,265 & 0,225 \\
\hline & N1-P0-K1 & $0,184 \mathrm{Ca}$ & 0,215 & 0,307 & 0,275 & 0,245 \\
\hline & N1-P1-K1 & $0,145 \mathrm{Ca}$ & 0,202 & 0,243 & 0,209 & 0,200 \\
\hline & Média & $0,162 \mathrm{~B}$ & $0,203 \mathrm{~B}$ & $0,312 \mathrm{~A}$ & $0,262 \mathrm{~A}$ & \\
\hline \multirow{9}{*}{90} & N0-P0-K0 & 0,281 & $0,349 \mathrm{Ca}$ & $0,658 \mathrm{Ba}$ & $0,883 \mathrm{Aa}$ & 0,543 \\
\hline & N0-P1-K0 & 0,237 & $0,308 \mathrm{Ba}$ & $0,635 \mathrm{Aa}$ & $0,670 \mathrm{Aab}$ & 0,463 \\
\hline & N0-P0-K1 & 0,225 & $0,325 \mathrm{Ba}$ & $0,695 \mathrm{Aa}$ & $0,795 \mathrm{Aab}$ & 0,510 \\
\hline & N0-P1-K1 & 0,217 & $0,352 \mathrm{Ba}$ & $0,627 \mathrm{Aa}$ & $0,725 \mathrm{Aab}$ & 0,480 \\
\hline & $\mathrm{N} 1-\mathrm{P} 0-\mathrm{K} 0$ & 0,189 & $0,342 \mathrm{Ba}$ & $0,602 \mathrm{Aa}$ & $0,624 \mathrm{Ab}$ & 0,439 \\
\hline & N1-P1-K0 & 0,165 & $0,359 \mathrm{Ba}$ & $0,597 \mathrm{Aa}$ & $0,742 \mathrm{Aab}$ & 0,466 \\
\hline & N1-P0-K1 & 0,174 & $0,364 \mathrm{Ba}$ & $0,669 \mathrm{Aa}$ & $0,670 \mathrm{Aab}$ & 0,469 \\
\hline & N1-P1-K1 & 0,155 & $0,295 \mathrm{Ba}$ & $0,649 \mathrm{Aa}$ & $0,760 \mathrm{Aab}$ & 0,465 \\
\hline & Média & $0,205 \mathrm{D}$ & $0,337 \mathrm{C}$ & $0,642 \mathrm{~B}$ & $0,734 \mathrm{~A}$ & \\
\hline \multirow{9}{*}{120} & N0-P0-K0 & $0,285 \mathrm{Da}$ & $0,555 \mathrm{Ca}$ & $1,067 \mathrm{Ba}$ & $1,618 \mathrm{Aa}$ & 0,881 \\
\hline & N0-P1-K0 & $0,258 \mathrm{Ca}$ & $0,531 \mathrm{Ba}$ & $1,294 \mathrm{Aa}$ & $1,381 \mathrm{Aab}$ & 0,866 \\
\hline & N0-P0-K1 & $0,287 \mathrm{Ca}$ & $0,618 \mathrm{Ba}$ & $1,351 \mathrm{Aa}$ & $1,472 \mathrm{Aab}$ & 0,932 \\
\hline & N0-P1-K1 & $0,246 \mathrm{Da}$ & $0,574 \mathrm{Ca}$ & $1,028 \mathrm{Ba}$ & $1,393 \mathrm{Aab}$ & 0,810 \\
\hline & $\mathrm{N} 1-\mathrm{P} 0-\mathrm{K} 0$ & $0,244 \mathrm{Ca}$ & $0,585 \mathrm{Ba}$ & $1,311 \mathrm{Aa}$ & $1,239 \mathrm{Aab}$ & 0,845 \\
\hline & N1-P1-K0 & $0,246 \mathrm{Ca}$ & $0,559 \mathrm{Ba}$ & $1,271 \mathrm{Aa}$ & $1,363 \mathrm{Aab}$ & 0,860 \\
\hline & N1-P0-K1 & $0,299 \mathrm{Ca}$ & $0,550 \mathrm{Ba}$ & $1,192 \mathrm{Aa}$ & $1,180 \mathrm{Ab}$ & 0,805 \\
\hline & N1-P1-K1 & $0,254 \mathrm{Da}$ & $0,525 \mathrm{Ca}$ & $1,142 \mathrm{Ba}$ & $1,533 \mathrm{Aab}$ & 0,864 \\
\hline & Média & 0,265 & 0,562 & 1,207 & 1,397 & \\
\hline
\end{tabular}

Em cada idade e cada adubação (linha), médias seguidas de pelo menos uma mesma letra maiúscula não diferem entre si pelo teste de Tukey ( $\mathrm{P}>0,05)$. Em cada idade e cada tubete (coluna), médias seguidas de pelo menos uma mesma letra minúscula não diferem entre si pelo teste de Tukey $(\mathrm{P}>0,05)$.

R. Árvore, Viçosa-MG, v.27, n.2, p.113-127, 2003 
apesar de a determinação do peso de matéria seca ser um processo destrutivo.

As médias da relação parte aérea/raiz (RPPAR) das mudas nas diferentes idades, fertilizações e tamanhos de tubetes estão no Quadro 9.

Analisando esse quadro verifica-se que esse parâmetro somente foi significativamente diferente (em nível de $5 \%$ de probabilidade), para os tamanhos dos tubetes, quando foram desconsideradas as idades e fertilizações.

Os resultados foram semelhantes aos conseguidos para outros parâmetros medidos, onde o tamanho da embalagem tem importância decisiva na produção de mudas de espécies florestais.
Analisando o Quadro 10, onde estão relacionadas as médias do índice de qualidade de Dickson (IQD) em diferentes idades, fertilizações e tamanhos de tubetes, pode-se verificar que o tamanho dos tubetes, apesar de promover diferenças nesse índice, só foi significativo (em nível de 5\% de probabilidade) para a idade de 120 dias. As idades e as fertilizações praticamente não foram responsáveis pelas diferenças.

O índice de qualidade de Dickson, apesar de ser mencionado como uma promissora medida morfológica integrada (Johnson \& Cline, 1991) e apontado como bom indicador da qualidade de mudas, por considerar para o seu cálculo a robustez e o equilíbrio da distribuição da biomassa, sendo ponderados vários parâmetros

Quadro 7 - Médias do peso de matéria seca total (TDMW) de mudas de Eucalyptus grandis em diferentes idades, adubações e tamanhos de tubetes

Table 7 -Averages of total dry matter weight (PMST) of Eucalyptus grandis seedlings at different ages (60, 90 and 120 days), fertilization and tube sizes

\begin{tabular}{|c|c|c|c|c|c|c|}
\hline \multirow{2}{*}{$\begin{array}{l}\text { Idade } \\
\text { (dias) }\end{array}$} & \multirow{2}{*}{ Adubação } & \multicolumn{4}{|c|}{ Tubete } & \multirow{2}{*}{ Média } \\
\hline & & $\mathrm{A}\left(50 \mathrm{~cm}^{3}\right)$ & $\mathrm{B}\left(110 \mathrm{~cm}^{3}\right)$ & $\mathrm{C}\left(200 \mathrm{~cm}^{3}\right)$ & $\mathrm{D}\left(280 \mathrm{~cm}^{3}\right)$ & \\
\hline \multirow{9}{*}{60} & $\mathrm{~N} 0-\mathrm{P} 0-\mathrm{K} 0$ & 0,337 & 0,543 & 0,939 & 1,159 & 0,745 \\
\hline & N0-P1-K0 & 0,340 & 0,490 & 0,881 & 0,843 & 0,638 \\
\hline & N0-P0-K1 & 0,347 & 0,553 & 0,925 & 0,902 & 0,682 \\
\hline & N0-P1-K1 & 0,303 & 0,453 & 0,779 & 0,965 & 0,625 \\
\hline & N1-P0-K0 & 0,291 & 0,483 & 0,653 & 0,947 & 0,593 \\
\hline & N1-P1-K0 & 0,253 & 0,471 & 0,897 & 0,963 & 0,646 \\
\hline & N1-P0-K1 & 0,341 & 0,551 & 0,796 & 0,956 & 0,746 \\
\hline & N1-P1-K1 & 0,290 & 0,502 & 0,687 & 0,716 & 0,545 \\
\hline & Média & $0,313 \mathrm{D}$ & $0,506 \mathrm{C}$ & $0,820 \mathrm{~B}$ & $0,931 \mathrm{~A}$ & \\
\hline \multirow{9}{*}{90} & $\mathrm{~N} 0-\mathrm{P} 0-\mathrm{K} 0$ & $0,711 \mathrm{Da}$ & $1,243 \mathrm{Ca}$ & $2,310 \mathrm{Ba}$ & $3,525 \mathrm{Aa}$ & 1,947 \\
\hline & N0-P1-K0 & $0,699 \mathrm{Ca}$ & $1,147 \mathrm{Ba}$ & $2,455 \mathrm{Aa}$ & $2,666 \mathrm{bc}$ & 1,742 \\
\hline & N0-P0-K1 & $0,903 \mathrm{Ca}$ & $1,127 \mathrm{Ca}$ & $2,649 \mathrm{Ba}$ & $3,163 \mathrm{ab}$ & 1,961 \\
\hline & N0-P1-K1 & $0,586 \mathrm{Da}$ & $1,240 \mathrm{Ca}$ & $2,303 \mathrm{Ba}$ & $2,983 \mathrm{ab}$ & 1,778 \\
\hline & $\mathrm{N} 1-\mathrm{P} 0-\mathrm{K} 0$ & $0,549 \mathrm{Da}$ & $1,235 \mathrm{Ca}$ & $2,232 \mathrm{Ba}$ & $2,648 \mathrm{bc}$ & 1,666 \\
\hline & N1-P1-K0 & $0,479 \mathrm{Da}$ & $1,179 \mathrm{Ca}$ & $2,359 \mathrm{Ba}$ & $3,183 \mathrm{ab}$ & 1,800 \\
\hline & N1-P0-K1 & $0,637 \mathrm{Da}$ & $1,351 \mathrm{Ca}$ & $2,394 \mathrm{Ba}$ & $2,857 \mathrm{bc}$ & 1,810 \\
\hline & N1-P1-K1 & $0,565 \mathrm{Ca}$ & $1,193 \mathrm{Ba}$ & $2,223 \mathrm{Aa}$ & $2,478 \mathrm{Ac}$ & 1,615 \\
\hline & Média & 0,576 & 1,214 & 2,366 & 2,938 & \\
\hline \multirow{9}{*}{120} & N0-P0-K0 & $0,941 \mathrm{Da}$ & $2,078 \mathrm{Ca}$ & $3,709 \mathrm{Ba}$ & $6,635 \mathrm{Aa}$ & 3,341 \\
\hline & N0-P1-K0 & $0,791 \mathrm{Da}$ & $1,945 \mathrm{Ca}$ & $4,290 \mathrm{Ba}$ & $5,565 \mathrm{ab}$ & 3,148 \\
\hline & N0-P0-K1 & $0,926 \mathrm{Da}$ & $2,183 \mathrm{Ca}$ & $4,568 \mathrm{Ba}$ & $5,783 \mathrm{ab}$ & 3,365 \\
\hline & N0-P1-K1 & 0,792 Da & $2,151 \mathrm{Ca}$ & $3,545 \mathrm{Ba}$ & $5,901 \mathrm{ab}$ & 3,097 \\
\hline & $\mathrm{N} 1-\mathrm{P} 0-\mathrm{K} 0$ & $0,819 \mathrm{Da}$ & $2,024 \mathrm{Ca}$ & $4,152 \mathrm{Ba}$ & $5,199 \mathrm{Ab}$ & 3,049 \\
\hline & $\mathrm{N} 1-\mathrm{P} 1-\mathrm{K} 0$ & $0,772 \mathrm{Da}$ & $2,160 \mathrm{Ca}$ & $4,261 \mathrm{Ba}$ & $5,793 \mathrm{ab}$ & 3,247 \\
\hline & $\mathrm{N} 1-\mathrm{P} 0-\mathrm{K} 1$ & $0,977 \mathrm{Ca}$ & $2,079 \mathrm{Ba}$ & $4,471 \mathrm{Aa}$ & $5,000 \mathrm{Ab}$ & 3,132 \\
\hline & N1-P1-K1 & $0,901 \mathrm{Da}$ & $1,998 \mathrm{Ca}$ & $4,058 \mathrm{Ba}$ & $5,093 \mathrm{Ab}$ & 3,013 \\
\hline & Média & 0,865 & 2,077 & 4,132 & 5,621 & \\
\hline
\end{tabular}

Em cada idade e cada adubação (linha), médias seguidas de pelo menos uma mesma letra maiúscula não diferem entre si pelo teste de Tukey (P>0,05). Em cada idade e cada tubete (coluna), médias seguidas de pelo menos uma mesma letra minúscula não diferem entre si pelo teste de Tukey (P>0,05). 
Quadro 8 - Médias da relação altura/peso da matéria seca da parte aérea (RHPMSPA) de mudas de Eucalyptus grandis em diferentes idades, adubações e tamanhos de tubetes

Table 8 - Average of height/shoot dry matter weight relation (HSDMWR) of Eucalyptus grandis seedlings at ages of 60, 90 and 120 days fertilization and sizes of tubes

\begin{tabular}{|c|c|c|c|c|c|c|}
\hline \multirow{2}{*}{$\begin{array}{l}\text { Idade } \\
\text { (dias) }\end{array}$} & \multirow{2}{*}{ Adubação } & \multicolumn{4}{|c|}{ Tubete } & \multirow{2}{*}{ Média } \\
\hline & & $\mathrm{A}\left(50 \mathrm{~cm}^{3}\right)$ & $\mathrm{B}\left(110 \mathrm{~cm}^{3}\right)$ & $\mathrm{C}\left(200 \mathrm{~cm}^{3}\right)$ & $\mathrm{D}\left(280 \mathrm{~cm}^{3}\right)$ & \\
\hline \multirow{9}{*}{60} & N0-P0-K0 & 49,37 & 39,53 & 24,37 & 26,16 & $34,86 \mathrm{~b}$ \\
\hline & N0-P1-K0 & 54,38 & 44,93 & 32,75 & 38,16 & $42,55 \mathrm{a}$ \\
\hline & N0-P0-K1 & 46,97 & 41,21 & 27,67 & 30,72 & $36,64 \mathrm{ab}$ \\
\hline & N0-P1-K1 & 53,35 & 43,74 & 32,82 & 27,55 & $39,36 \mathrm{ab}$ \\
\hline & $\mathrm{N} 1-\mathrm{P} 0-\mathrm{K} 0$ & 55,61 & 45,92 & 34,55 & 30,38 & $41,61 \mathrm{a}$ \\
\hline & N1-P1-K0 & 53,10 & 44,90 & 27,13 & 28,51 & $38,41 \mathrm{ab}$ \\
\hline & $\mathrm{N} 1-\mathrm{P} 0-\mathrm{K} 1$ & 53,82 & 43,48 & 30,22 & 26,47 & $38,50 \mathrm{ab}$ \\
\hline & N1-P1-K1 & 58,00 & 45,33 & 31,08 & 29,17 & $40,89 \mathrm{ab}$ \\
\hline & Média & $53,07 \mathrm{~A}$ & $48,57 \mathrm{~B}$ & $30,07 \mathrm{C}$ & $29,64 \mathrm{C}$ & \\
\hline \multirow{9}{*}{90} & N0-P0-K0 & 40,32 & 28,38 & 16,91 & 18,57 & 26,04 \\
\hline & N0-P1-K0 & 39,37 & 28,97 & 17,88 & 24,27 & 27,62 \\
\hline & N0-P0-K1 & 33,96 & 31,47 & 19,97 & 19,05 & 26,11 \\
\hline & N0-P1-K1 & 40,73 & 28,05 & 15,68 & 19,62 & 26,02 \\
\hline & $\mathrm{N} 1-\mathrm{P} 0-\mathrm{K} 0$ & 41,69 & 30,22 & 22,74 & 23,16 & 29,45 \\
\hline & N1-P1-K0 & 44,38 & 30,38 & 21,84 & 16,67 & 28,32 \\
\hline & N1-P0-K1 & 38,38 & 27,73 & 18,16 & 17,53 & 25,45 \\
\hline & N1-P1-K1 & 40,61 & 29,46 & 20,93 & 21,22 & 28,05 \\
\hline & Média & $39,93 \mathrm{~A}$ & $29,33 \mathrm{~B}$ & $19,26 \mathrm{C}$ & $20,01 \mathrm{C}$ & \\
\hline \multirow{9}{*}{120} & N0-P0-K0 & 33,32 & 19,37 & 13,72 & 12,29 & 19,67 \\
\hline & N0-P1-K0 & 45,14 & 23,77 & 14,92 & 14,58 & 24,60 \\
\hline & N0-P0-K1 & 36,43 & 21,03 & 16,29 & 12,67 & 21,60 \\
\hline & N0-P1-K1 & 34,87 & 22,43 & 17,34 & 12,76 & 21,85 \\
\hline & $\mathrm{N} 1-\mathrm{P} 0-\mathrm{K} 0$ & 34,00 & 23,60 & 17,20 & 14,85 & 21,54 \\
\hline & $\mathrm{N} 1-\mathrm{P} 1-\mathrm{K} 0$ & 38,74 & 20,36 & 17,02 & 11,38 & 21,87 \\
\hline & N1-P0-K1 & 33,04 & 24,01 & 11,78 & 12,81 & 20,41 \\
\hline & N1-P1-K1 & 34,61 & 24,22 & 14,56 & 13,24 & 21,66 \\
\hline & Média & $36,27 \mathrm{~A}$ & $22,35 \mathrm{~B}$ & $15,35 \mathrm{C}$ & $13,07 \mathrm{C}$ & \\
\hline
\end{tabular}

Em cada idade e cada adubação (linha), médias seguidas de pelo menos uma mesma letra maiúscula não diferem entre si pelo teste de Tukey ( $\mathrm{P}>0,05)$. Em cada idade e cada tubete (coluna), médias seguidas de pelo menos uma mesma letra minúscula não diferem entre si pelo teste de Tukey ( $\mathrm{P}>0,05)$.

importantes (Fonseca, 2000), é de difícil determinação, por envolver parâmetros destrutivos.

No caso específico de mudas de Eucalyptus grandis esse índice não seria recomendado, porque além das considerações feitas as diferenças não foram significativas estatisticamente, a não ser na idade de 120 dias, quando as mudas já estavam com alturas muito além das consideradas com padrão para serem plantadas.

\section{CONCLUSÕES}

Com base nos resultados, pode-se concluir para a produção de mudas de Eucalyptus grandis que:

- O volume do tubete é importante e deve ser considerado.

R. Árvore, Viçosa-MG, v.27, n.2, p.113-127, 2003
- Apesar de os melhores crescimentos terem sido obtidos nos maiores tubetes, esses não são recomendáveis, uma vez que as alturas das mudas estão acima das tecnicamente ótimas para o plantio, além de o custo de produção ser maior.

- Aos 60 dias de idade as mudas ainda estavam pequenas e bastante tenras, sem o endurecimento adequado para o plantio no campo.

- Aos 120 dias após a semeadura o crescimento das raízes e da altura das mudas foi afetado, mesmo nos tubetes de maiores volumes, não sendo essa a idade indicada.

- Os tubetes de 50 e de $110 \mathrm{~cm}^{3}$ de volume devem ser indicados para mudas com 90 dias de idade. 
Quadro 9 - Médias da relação parte aérea/raiz (RPPAR) de Eucalyptus grandis em diferentes idades, adubações e tamanhos de tubetes

Table 9 - Averages of shoot dry matter weight/root dry matter weight relation (SDMRDR) of Eucalyptus grandis seedlings at different ages (60, 90 and 120 days), fertilization and tube sizes

\begin{tabular}{|c|c|c|c|c|c|c|}
\hline \multirow{2}{*}{$\begin{array}{l}\text { Idade } \\
\text { (dias) }\end{array}$} & \multirow{2}{*}{ Adubação } & \multicolumn{4}{|c|}{ Tubete } & \multirow{2}{*}{ Média } \\
\hline & & $\mathrm{A}\left(50 \mathrm{~cm}^{3}\right)$ & $\mathrm{B}\left(110 \mathrm{~cm}^{3}\right)$ & $\mathrm{C}\left(200 \mathrm{~cm}^{3}\right)$ & $\mathrm{D}\left(280 \mathrm{~cm}^{3}\right)$ & \\
\hline \multirow{9}{*}{60} & N0-P0-K0 & 0,93 & 1,49 & 2,43 & 2,54 & 1,85 \\
\hline & N0-P1-K0 & 0,87 & 1,85 & 1,39 & 2,62 & 1,68 \\
\hline & N0-P0-K1 & 1,03 & 1,47 & 2,20 & 2,91 & 1,90 \\
\hline & N0-P1-K1 & 1,03 & 1,70 & 1,57 & 2,62 & 1,73 \\
\hline & N1-P0-K0 & 0,91 & 1,69 & 2,33 & 2,52 & 1,86 \\
\hline & N1-P1-K0 & 1,04 & 1,92 & 2,08 & 2,81 & 1,96 \\
\hline & N1-P0-K1 & 0,86 & 1,69 & 1,94 & 2,62 & 1,78 \\
\hline & N1-P1-K1 & 1,00 & 1,52 & 2,01 & 2,64 & 1,79 \\
\hline & Média & $0,96 \mathrm{C}$ & $1,67 \mathrm{~B}$ & $1,99 \mathrm{~B}$ & $2,66 \mathrm{~A}$ & \\
\hline \multirow{9}{*}{90} & N0-P0-K0 & 1,60 & 2,60 & 2,67 & 3,08 & 2,49 \\
\hline & N0-P1-K0 & 2,07 & 2,76 & 2,86 & 2,99 & 2,67 \\
\hline & N0-P0-K1 & 2,20 & 2,53 & 2,83 & 3,09 & 2,66 \\
\hline & N0-P1-K1 & 1,83 & 2,63 & 2,88 & 3,14 & 2,62 \\
\hline & $\mathrm{N} 1-\mathrm{P} 0-\mathrm{K} 0$ & 1,94 & 2,68 & 3,00 & 3,29 & 2,73 \\
\hline & N1-P1-K0 & 1,90 & 2,37 & 3,05 & 3,39 & 2,68 \\
\hline & N1-P0-K1 & 2,86 & 2,78 & 2,59 & 3,26 & 2,87 \\
\hline & N1-P1-K1 & 2,63 & 3,04 & 2,44 & 2,28 & 2,60 \\
\hline & Média & $2,13 \mathrm{~B}$ & $2,67 \mathrm{~B}$ & $2,79 \mathrm{~B}$ & $3,07 \mathrm{~A}$ & \\
\hline \multirow{9}{*}{120} & N0-P0-K0 & 2,38 & 2,77 & 2,50 & 3,10 & 2,69 \\
\hline & N0-P1-K0 & 2,12 & 2,74 & 2,40 & 3,03 & 2,57 \\
\hline & N0-P0-K1 & 2,25 & 2,54 & 2,53 & 3,05 & 2,59 \\
\hline & N0-P1-K1 & 2,23 & 2,77 & 2,52 & 3,25 & 2,69 \\
\hline & $\mathrm{N} 1-\mathrm{P} 0-\mathrm{K} 0$ & 2,41 & 2,47 & 2,20 & 3,15 & 2,56 \\
\hline & $\mathrm{N} 1-\mathrm{P} 1-\mathrm{K} 0$ & 2,16 & 2,89 & 2,37 & 3,37 & 2,70 \\
\hline & N1-P0-K1 & 2,28 & 2,81 & 2,78 & 3,31 & 2,80 \\
\hline & N1-P1-K1 & 2,54 & 2,80 & 2,55 & 2,38 & 2,57 \\
\hline & Média & $2,30 \mathrm{C}$ & $2,72 \mathrm{~B}$ & $2,48 \mathrm{C}$ & $3,08 \mathrm{~A}$ & \\
\hline
\end{tabular}

Em cada idade e cada adubação (linha), médias seguidas de pelo menos uma mesma letra maiúscula não diferem entre si pelo teste de Tukey ( $\mathrm{P}>0,05)$. Em cada idade e cada tubete (coluna), médias seguidas de pelo menos uma mesma letra minúscula não diferem entre si pelo teste de Tukey ( $\mathrm{P}>0,05)$.

- Aos 90 dias de idade os volumes dos tubetes começam a restringir o crescimento das mudas, o que permite o maior crescimento diamétrico e a maior produção de matéria seca, promovendo o seu maior endurecimento.

\section{REFERÊNCIAS BIBLIOGRÁFICAS}

BARROS, N. F. et al. Efeitos de recipientes na sobrevivência e no crescimento de mudas de Eucalyptus grandis no viveiro e no campo. Revista Árvore, v. 2, n. 2, p. 141-151, 1978.

BERTOLANI, F. et al. Influência dos recipientes e dos métodos de semeadura na formação de mudas de Pinus caribaea Morelet var. hondurensis. IPEF, v. 11, p. 71-77, 1975.
BÖHM, W. Methods of studying root systems. Berlin: SpringerVeriag, 1979. $188 \mathrm{p}$.

BRISSETTE, J. C. Summary of discussions about seedling quality. Separata de: SOUTHERN NURSERY

CONFERENCES, (1984.: Alexandria, LA). Proceedings... New Orleans: USDA. Forest Service. Southern Forest Experiment Station, 1984. p. 127-128.

CAMPINHOS Jr., E.; IKEMORI, Y. K. Nova técnica para produção de mudas de essências florestais. IPEF, v. 47, n. 23, p. 4752, 1983.

CARNEIRO, J. G. A.; RAMOS, A. Influência da altura aérea, diâmetro de colo e idade de mudas de Pinus taeda sobre a sobrevivência e desenvolvimento após 15 meses e aos seis anos após o plantio. In: SEMINÁRIO DE SEMENTES E VIVEIROS FLORESTAIS, 10., 1981, Curitiba. Anais... Curitiba: FUPEF, 1981. p. 91-110.

R. Árvore, Viçosa-MG, v.27, n.2, p.113-127, 2003 
CARNEIRO, J. G. A. Influência dos fatores ambientais, das técnicas de produção sobre o desenvolvimento de mudas florestais e a importância dos parâmetros que definem sua qualidade. In: FLORESTAS PLANTADAS NOS NEOTRÓPICOS COMO FONTE DE ENERGIA. Anais... Viçosa: Universidade Federal de Viçosa, 1983. p. 10-24.

CARNEIRO, J. G. A. Efeito da densidade sobre o desenvolvimento de alguns parâmetros morfofisiológicos de mudas de Pinus taeda $\mathrm{L}$. em viveiro e após o plantio. Curitiba: Universidade Federal do Paraná, 1985. 106 p. (Concurso para Professor Titular).

CARNEIRO, J. G. A. Influência de recipientes e de estações de semeadura sobre o comportamento do sistema radicular e dos parâmetros morfológicos de mudas de Pinus taeda e Pinus elliottii L. Curitiba: Universidade Federal do Paraná, 1987. 81 p.

CARNEIRO, J. G. A. Produção e controle de qualidade de mudas florestais. Curitiba: UFPR/FUPEF, 1995. 451 p.

DANIEL, T.; HELMS, J.; BACKER, F. Princípios de silvicultura. 2.ed. México: McGraw-Hill, 1982. 492 p.

FAGUNDES, N. B.; FIALHO, A. A. Produção de mudas de Eucalyptus via sementes no sistema tubetes na COPENER. IPEF. Série Técnica, v. 4, n. 13, p. 25-29, 1987.

FERREIRA, M. G. M. Sistema radicular na avaliação da qualidade de muda. Viçosa: SIF, 1985. p. 31-32 (Informativo SIF)

FONSECA, E. P. Padrão de qualidade de mudas de Trema mícrantha (L.) Blume., Cedrela fissilis Veli. e Aspidosperma polyneuron Müll Arg. produzidas sob diferentes períodos de sombreamento. 2000. 113 f. Tese (Doutorado) - Universidade Estadual Paulista, Jabotical, 2000 .

GOMES, J. M. et al. Efeitos de recipientes e substratos na produção de mudas de Eucalyptus grandis W. Hill ex Maiden. Revista Árvore, v. 1, n. 2, p. 167-172, 1977.

GOMES, J. M. et al. Influência do tratamento prévio do solo com brometo de metila no crescimento de mudas de Pinus caribaea var. hondurensis em viveiro. Brasil Florestal, v. 9, n. 35, p. 18-23, 1978.

GOMES, J. M. et al. Influência do tamanho da embalagem plástica na produção de mudas de Pinus caribaea var. hondurensis. Viçosa: SIF, 1980. p. 7-16 (Boletim Técnico, 9)

R. Árvore, Viçosa-MG, v.27, n.2, p.113-127, 2003
GOMES, J. M. et al. Efeito do tamanho de recipientes plásticos na formação de florestas de eucaliptos. Viçosa: SIF, 1981. p. 1-12 (Boletim Técnico, 4).

GOMES, J. M.; COUTO, L. Produção de mudas de folhosas. In: FLORESTAS PLANTADAS NOS NEOTRÓPICOS COMO FONTE DE ENERGIA. Resumos... Viçosa: Universidade Federal de Viçosa, 1983. p. 25-35.

GOMES, J. M.; COUTO, L.; PEREIRA, A. R. Uso de diferentes substratos e suas misturas na produção de mudas de Eucalyptus grandis por meio de semeadura direta em tubetes e em bandejas de isopor. Revista Arvore, v. 9, n. 1, p. 8-86, 1985.

GOMES, J. M. et al. Influência do tamanho da embalagem plástica na produção de mudas de Ipê (Tabebuia serratifolia) de Copaíba (Copaifera langsdorffii) e de Angico Vermelho (Piptadenia peregrina). Revista Árvore, v. 14 , n. 1 , p. 26-34, 1990.

GOMES, J. M. et al. Efeito de diferentes substratos na produção de mudas de Eucalyptus grandis W. Hill ex Maiden, em "Win-Strip". Revista Árvore, v. 15, n. 1, p. 35-42, 1991.

GONÇALVES, J. L. M. Uso de resíduo industrial como substrato para produção de mudas em tubetes na Ripasa Florestal S.A. IPEF, Série Técnica, v. 4, n. 13, p. 18-33, 1987.

GONZALES, R. A. Estudio sobre el comportamiento en vivero de Pinus caribaea var. caribaea cultivado en envases de polietileno de 12 dimensiones diferentes. Revista Forestal Baracoa, v. 18, n. 1, p. 39-51, 1988.

HENRIQUES, E. P. Produção de mudas na ACESITA ENERGÉTICA S.A. IPEF, Série Técnica, v. 4, n. 13, p. 13-17, 1987.

JOHNSON, J. D.; CLINE, P. M. Seedling quality of southern pines. In: DUREYA, M. L.; DOUGHERTY, P. M. (Eds.). Forest regeneration manual. Dordrecht: Kluwer Academic Publishers, 1991. p. 143-162.

NEVES, J. C. L.; GOMES, J. M.; NOVAIS, R. F. Fertilização mineral de mudas de eucalípto. In: BARROS, N. F.; NOVAIS, R. F. (Eds.) Relação solo-eucalípto. Viçosa: Folha de Viçosa, 1990. p. 99-126.

NOVAES, A. B. Avaliação morfológica da qualidade de mudas de Pinus taeda $L$. produzidas em raiz nua e em diferentes tipos de recipientes. 1998. $116 \mathrm{f}$. Tese (Doutorado) - Universidade Federal do Paraná, Curitiba, 1998. 
PARVIAINEN, J. V. Initial development of root systems of various types of nursery stock for scots pine. Folia Forestalia, v. 268, p. 2-21, 1976.

PARVIAINEN, J. V. Qualidade e avaliação de qualidade de mudas florestais. In: SEMINÁRIO DE SEMENTES E VIVEIROS FLORESTAIS, 1., 1981, Curitiba. Anais... Curitiba: FUPEF, 1981. p. 59-90.

PARVIAINEN, J. V.; TERVO, L. A new approach for production of containerized coniferous seedlings using peat sheets coupled with root prunning. Forestry Suppiement, v. 62 , p. 87-94, 1989.

REIS, G. G.; REIS, M. G. F.; MAESTRI, M. Crescimento de Eucalyptus camaldulensis, E. grandis e E. cloeziana sob diferentes níveis de restrição radicular. Revista Árvore, v. 13, n. 1, p. 1-18, 1989.

ROCHA, D.; BRAGA, J. M. Adubação fosfatada em eucaliptos no viveiro. 1. Interação entre espécies de eucaliptos e fontes de fósforo. In: CONGRESSO FLORESTAL BRASILEIRO, 4., 1982, Belo horizonte. Anais... Belo Horizonte: 1982. p. 455-459.
SANTOS, C. B. et al. Efeito do volume de tubetes e tipos de substratos na qualidade de mudas de Cryptomeria japonica (L. f.) D. Don. Ciência Florestal, v. 10, n. 2, p. 1-15. 2000.

SHIMIDT-VOGT, H. Morpho-physiological quality of forest tree seedlings. In: SIMPÓSIO INTERNACIONAL: MÉTODOS DE PRODUÇÃO E CONTROLE DE QUALIDADE DE SEMENTES E MUDAS FLORESTAIS, 1984, Curitiba. Anais... Curitiba: FUPEF, 1984. p. 366378.

VENTURIM, N. Efeito de recipiente no desenvolvimento de mudas de Eucalyptus grandis W. Hill ex Maiden. In: CONGRESSO FLORESTAL BRESILEIRO, 3., 1978, Manaus. Anais... Manaus: Sociedade Brasileira de Silvicultura, 1978. p. 357-357.

ZANI FILHO, J.; BALLONI, E. A.; STAPE, J. L. Viveiro de mudas florestais - Análise de um sistema operacional atual e perspectivas futuras. Piracicaba: IPEF, 1989. (Circular Técnica, 167) 